\title{
Disrupted Gamma-Band Neural Oscillations During Coherent Motion Perception in Heavy Cannabis Users
}

\author{
Patrick D Skosnik*,', Giri P Krishnan ${ }^{2}$, Deepak C D'Souza', William P Hetrick ${ }^{\mathbf{3}}$ and Brian F O'Donnell ${ }^{\mathbf{3}}$ \\ 'Department of Psychiatry, Yale University School of Medicine, New Haven, CT, USA; '2Department of Cell Biology and Neuroscience, University \\ of California, Riverside, Riverside, CA, USA; ${ }^{3}$ Department of Psychological and Brain Sciences, Indiana University, Bloomington, IN, USA
}

\begin{abstract}
Previous work in animals and humans has shown that exogenous cannabinoids disrupt time-locked, evoked gamma oscillations (30$80 \mathrm{~Hz}$ ). However, no studies to date have examined the effect of cannabis on non-time-locked, induced gamma oscillations during more complex Gestalt perception. The current study therefore utilized electroencephalography (EEG) to examine gamma oscillations during coherent motion perception in heavy cannabis users and controls. Chronic cannabis users $(n=24 ; 12 \mathrm{~h}$ abstinence before study; positive I I-nor-9-carboxy-delta-9-tetrahydrocannabinol urine levels) and cannabis-naive controls $(n=23)$ were evaluated. Stimuli consisted of random dot kinetograms (RDKs) that subjects passively viewed during three different conditions: coherent motion, incoherent motion, and static. Time $\times$ frequency analysis on EEG data was performed using Fourier-based mean trial power (MTP). Transient event-related potentials (ERPs) to stimulus onset (visual NIO0 and P200 components) were also evaluated. The results showed that the coherent motion condition produced a robust increase in neural activity in the gamma range (induced power from 40 to $59 \mathrm{~Hz}$ ) as compared with the incoherent motion and static conditions. As predicted, the cannabis group showed significant reductions in induced gamma power in the coherent condition relative to healthy controls. No differences were observed between the groups in the NI00 or P200 components, indicating intact primary sensory processing. Finally, cannabis users showed a trend toward increased scores on the Chapman Perceptual Aberration Scale (PAS) that was positively correlated with total years of active cannabis use. These data suggest that cannabis use may interfere with the generation of induced gamma-band neural oscillations that could in part mediate the perceptualaltering effects of exogenous cannabinoids.

Neuropsychopharmacology (2014) 39, 3087-3099; doi:I0.1038/npp.2014.166; published online I3 August 20I4
\end{abstract}

\section{INTRODUCTION}

Although cannabis has consistently been the most commonly used illicit drug in the United States (SAMHSA, 2012), the deleterious consequences of its use have only recently been recognized. For example, there is now convincing evidence that persistent cannabis use, particularly during adolescence, is associated with lasting impairments in perceptual and cognitive function (Meier et al, 2012; Semple et al, 2003; Skosnik et al, 2012; Solowij et al, 2002). Furthermore, heavy use of cannabis is now known to be a risk factor for the development of psychiatric disorders, most notably schizophrenia (Large et al, 2011; Moore et al, 2007). Most importantly, with the legalization of medicinal cannabis (Kleber and DuPont, 2012; Procon.org., 2011), the decriminalization of cannabis in some states in the United States (Bly, 2012), the high rates (ONDCP OoNDCP, 2008) and earlier age of onset of cannabis use (Johnston et al,

\footnotetext{
*Correspondence: Dr PD Skosnik, Department of Psychiatry, Yale University, Yale University School of Medicine, 300 George Street, New Haven, CT 06510, USA, Tel: +1 812320 2521, Fax: + I 203937 4860, E-mail: patrick.skosnik@yale.edu

Received 7 February 2014; revised 9 June 2014; accepted 10 June 2014; accepted article preview online 3 July 2014
}

2012), the increasing potency of cannabis (Mehmedic et al, 2010), and the recreational use of highly potent synthetic cannabinoids (eg, Spice and K-2) (Johnson et al, 2011; Vardakou et al, 2010), there is an urgent need to understand the neural mechanisms underlying the perceptual and cognitive effects of exogenous cannabinoids.

Cannabis, and its primary psychoactive constituent $\Delta^{9}$-tetrahydrocannabinol (THC) (Gaoni and Mechoulam, 1971), affects the brain through the activation of central cannabinoid-1 receptors (CB1Rs) (Devane et al, 1988; Pertwee et al, 2010). CB1Rs, which are the most highly expressed metabotropic receptors in the mammalian brain, are primarily localized to the cerebral cortex, basal ganglia, hippocampus, and cerebellum (Egertova and Elphick, 2000; Eggan and Lewis, 2007; Glass et al, 1997; Herkenham et al, 1990; Pertwee, 1997, 1999; Tsou et al, 1998). In the cerebral cortex and hippocampus, presynaptic CB1Rs inhibit the release of $\gamma$-aminobutyric acid (GABA) from cholecystokinin (CCK)-containing interneurons (Ali and Todorova, 2010; Bacci et al, 2004; Bodor et al, 2005; Eggan and Lewis, 2007; Eggan et al, 2010; Foldy et al, 2006; Hill et al, 2007; Katona et al, 2000). One of the primary functions of interneuron networks is the generation and maintenance of gamma-range $(30-80 \mathrm{~Hz})$ neural oscillations (Buzsaki and Wang, 2012; Gonzalez-Burgos and Lewis, 2008; Traub et al, 
1996, 2003; Uhlhaas and Singer, 2010; Whittington et al, 1995) that are thought to play a key role in sensory registration, the integration and binding of perceptual features, associative learning, and conscious awareness (Melloni et al, 2007; Singer, 1999; Uhlhaas et al, 2009; Wang, 2010; Whittington et al, 2000). Consequently, it has been suggested that exogenous cannabinoids may interfere with normal perception and cognition via the desynchronization of neural oscillations in the gamma range (Skosnik et al, 2006a).

In support of this postulate, in vitro slice studies have demonstrated that the application of both CB1R agonists (Hajos et al, 2000) and inverse agonists (Morgan et al, 2008) can disrupt the ability of neural networks to oscillate at gamma frequencies. Several in vivo animal studies utilizing local field potentials (LFPs) have also shown that exogenous cannabinoids can disrupt gamma rhythms (Hajos et al, 2008; Robbe et al, 2006). For example, Hajos et al (2008) observed that rats engaged in an auditory sensory gating paradigm exhibited decreases in gamma (and theta) power to click stimuli after the administration of the CB1R agonist CP-55940. These findings were CB1R specific, as the alterations in gamma oscillations were reversed by the CB1R antagonist AM-251. Most recently, Sales-Carbonell et al (2013) utilized neocortical electrocorticograms in mice and found that systemic administration of CP-55940 decreased the amplitude of neural oscillations $>12 \mathrm{~Hz}$ (ie, beta and gamma bands). Just as in the study of Hajos et al (2008), this decrease was blocked by the coadministration of AM-251 (Sales-Carbonell et al, 2013).

Regarding humans studies, several experiments have demonstrated that chronic cannabis users show evidence of altered gamma rhythms utilizing both evoked and steadystate electroencephalography (EEG) (Edwards et al, 2009; Skosnik et al, , 2006a, 2012). EEG is ideal for the study of neural oscillations, as the signals detected represent actual neural events (summed postsynaptic field potentials), and are recorded with millisecond-range temporal resolution (Luck et al, 2011). The types of neural oscillations in human EEG studies are typically classified as evoked, steady state, or induced (Bertrand and Tallon-Baudry, 2000; Galambos, 1992). Transient, time-locked EEG responses typically occur a few hundred milliseconds after the presentation of discrete sensory stimuli (tones or clicks), are phase-locked to stimulus onset, and are termed evoked oscillations (Pantev et al, 1991; Roach and Mathalon, 2008). Periodic/rhythmic stimuli (clicks or flashes) presented at specific frequencies can be used to entrain the EEG to a particular phase and frequency, and are utilized to test the capacity of neural networks to oscillate at functionally relevant frequencies (eg, gamma). These are often referred to as auditory or visual steady-state responses (Galambos et al, 1981; Kwon et al, 1999; Picton et al, 2003; Spencer et al, 2008). Finally, gamma oscillations can occur at variable phases or latencies with respect to stimulus onset, particularly during perceptual and cognitive tasks. These latency-varying responses are collectively referred to as induced oscillations. Induced gamma rhythms typically occur later than evoked oscillations ( 200-500 ms after stimulus onset), and are cancelled out after standard EEG trial averaging (as is used in the processing of evoked and steady-state responses) (Herrmann and Knight, 2001; Krishnan et al, 2005; Roach and Mathalon, 2008).
Using an auditory sensory gating paradigm similar to that utilized by Hajos et al (2008), Edwards et al (2009) demonstrated significant reductions in evoked gamma power and phase locking to click stimuli in chronic cannabis users (Edwards et al, 2009). Similarly, Skosnik et al (2006a; 2012) observed decreases in steady-state $40 \mathrm{~Hz}$ spectral power during an auditory entrainment paradigm that correlated with age of onset of cannabis use (Skosnik et al, 2012). These data thus provided the first evidence in humans that exogenous cannabinoids can disrupt evoked and steady-state gamma rhythms. However, no studies to date have examined whether cannabinoids can affect induced oscillations, particularly in the context of more complex perceptual processing.

As alluded to above, induced gamma oscillations may represent a neural correlate for various higher perceptual and cognitive processes including learning and memory, visual object representation, and perceptual binding (Bertrand and Tallon-Baudry, 2000; Buzsaki and Draguhn, 2004; Kaiser and Lutzenberger, 2003; Singer, 1999; TallonBaudry, 2009). Hence, whereas early evoked gamma rhythms are likely involved in sensory registration and the encoding of basic stimulus features, induced gamma oscillations may play a key role in the synchronization or 'binding' of neural assemblies involved in the generation of coherent cortical representations (ie, Gestalt perception). One domain where induced gamma has been shown to be especially relevant is visual motion perception. Motion perception, particularly coherent motion perception, requires the integration of local motion signals from various parts of the visual field into a global percept of two-dimensional motion (that likely occurs in area V5/MT) (Andersen, 1997; Born and Bradley, 2005; Heeger et al, 1999; Khayat et al, 2010; Muckli et al, 2002; Snowden et al, 1991). This integration of local motion signals from striate and prestriate visual cortices could be accomplished by gamma-range synchronization of neural populations within area MT. Indeed, numerous animal and human studies have shown that gamma power increases during the perception of coherent motion (Gray et al, 1990; Khayat et al, 2010; Krishnan et al, 2005; Kruse and Eckhorn, 1996; Lutzenberger et al, 1995; Muller et al, 1997; Naue et al, 2011; Schanze and Eckhorn, 1997; Siegel et al, 2007; Swettenham et al, 2009). For example, in a human EEG study, Krishnan et al (2005) utilized random dot kinetograms (RDKs) to demonstrate that coherent motion increased induced gamma power compared with incoherent or static stimuli. Similar results were observed in a human magnetoencephalography (MEG) study (Siegel et al, 2007), wherein gamma-band activity to coherent stimuli peaked in the lateral occipitotemporal cortex (an area corresponding to the visual motion area MT). Interestingly, in primate brain, area MT contains nearly twice the number of CB1Rs as compared with primary visual cortex (Eggan and Lewis, 2007). This, along with the role of CB1Rs in modulating GABA-mediated network oscillations discussed above, provides the impetus for studying the effect of chronic cannabinoids on gamma rhythms during motion perception.

The current study therefore examined the effect of chronic cannabis use on induced gamma oscillations utilizing a well-validated coherent motion perception paradigm (Brecht et al, 2001; Krishnan et al, 2005; Kruse and Hoffmann, 2002; Siegel et al, 2007). Based on previous animal and human work, it was hypothesized that the cannabis group would 
exhibit decreased induced gamma power during the perception of coherent motion. It was further predicted that cannabis users would exhibit intact visual event-related potentials (N100 and P200) to stimulus onset, indicating intact primary visual processing.

\section{MATERIALS AND METHODS}

\section{Subjects}

Current cannabis users $(n=24)$ and healthy drug-naive controls $(n=23)$ were recruited from the local university community, paid for their participation, and written informed consent was obtained from each. Table 1 illustrates basic demographic information as well as drug/alcohol use rates. There were no significant differences between the groups in age, years of education, or WAIS scores (Table 1).

The inclusion criteria were as follows: (1) For the cannabis group: current cannabis consumption (smoked joints) at the rate of at least once per week during the past month, a positive urine toxicology screen for THC metabolites (11-nor- $\Delta$-9-THC-9-carboxylic acid), no other illicit substance use during the past 3 months (including a negative urine toxicology screen for other illicit drugs), and no DSM-IV diagnosis of Axis I or II disorders except cannabis abuse or dependence; (2) For the control group: no history of illicit substance use, a negative urine toxicology screen for all drugs tested, and no history of psychiatric illness (Axis I or II); (3) For all participants: ages 18-35 years, completion of high school education, no family history of schizophrenia or bipolar disorder, no history of cardiovascular disease, hearing problems, neurological disease, learning disability, or head injury resulting in loss of consciousness. In addition, participants were excluded if they reported consumption of more than 2 alcoholic drinks per day ( 1 per day for females). The cannabis group druguse inclusion criteria (minimum cannabis use at least once per week; $24 \mathrm{~h}$ abstinence) was chosen to minimize acute cannabis effects, while retaining possible neurophysiological effects from altered CB1 activity. Human studies indicate that $80-90 \%$ of the total amount of THC is excreted within 5 days, and hence a minimum use of once per week enabled detection of THC metabolites (Hunt and Jones, 1980). Furthermore, previous work has shown that cannabis exposure of as little as once per week is enough to disrupt the behavioral and neuroendocrine response to THC (D'Souza et al, 2008). However, it should be noted that this requirement was simply a minimum for inclusion into the cannabis group, and the mean level of use was much higher (mean joints per week $=11.4 ; \mathrm{SD}=8.5$; see Table 1 ).

\section{Clinical Interviews, Questionnaires, and Drug-Use Assessment}

The Structured Clinical Interview for DSM-IV Axis I and II Disorders (SCID I and SCID II) were administered to assess current and past history of psychopathology. The SCID I module $\mathrm{E}$ and a locally developed drug-use questionnaire based on a timeline followback approach were used to ascertain current and past diagnoses for alcohol and substance abuse and dependence. Levels of cannabis consumption (estimated number of joints) were determined via the interview and questionnaire for lifetime, the past six 6,3 months, 1 month, and then for the week before the test session as has been described previously (Fridberg et al, 2011; Skosnik et al, 2006a, 2008, 2012). Participants were instructed to consider each day of the week and indicate, for an average week, how much they consumed per drug-use occasion for each length of time assessed. Age of first use, average number of joints smoked per week during the past month, and time since last use are reported in Table 1.

Urine drug screens (Q10-1, Proxam) were administered immediately preceding EEG testing in order to corroborate self-reports from the drug questionnaire and clinical

Table I Subject Demographics, WAIS and PAS Scores, and Substance Use Characteristics (Mean (SD))

\begin{tabular}{|c|c|c|c|}
\hline & Cannabis users $(n=24)$ & Controls $(n=23)$ & $P$-value \\
\hline Age (years) & $21.4(2.7)$ & $21.6(3.0)$ & $p=0.46$ \\
\hline Education (years) & $14.5(1.5)$ & $15.0(1.7)$ & $p=0.14$ \\
\hline WAIS (piccom) scores & $12.0(0.5)$ & $12.7(0.6)$ & $p=0.34$ \\
\hline WAIS (digit) scores & $10.7(0.4)$ & । $1.7(0.6)$ & $p=0.15$ \\
\hline Perceptual aberration scale (PAS) scores & $3.2(6.1)$ & $1.2(1.9)$ & $p=0.1$ \\
\hline Average number of alcoholic drinks/week (past month) & $4.6(4.1)$ & $0.9(2.5)$ & $p<\mathbf{0 . 0 0 1}$ \\
\hline Average number of cigarettes/week (past month) & $3.4(5.9)$ & I.I (4.2) & $p=0.12$ \\
\hline Age of first cannabis use & I5.4 (1.5) & - & - \\
\hline Total years of cannabis use & $5.6(3.0)$ & - & - \\
\hline
\end{tabular}

${ }^{\mathrm{a}}$ Results of $\chi^{2}$ test.

Note that WAIS version was the WAIS-III. Subscales included were picture completion (piccom), digit symbol (digit), similarities (sim), and digit span (dspan) Bold value indicates statistical significance. 
interviews. The Q10-1 kit screens for cannabis (THC-COOH; $50 \mathrm{ng} / \mathrm{ml}$ sensitivity), opiates, amphetamines, cocaine, MDMA (ecstasy), tricyclic antidepressants, phencyclidine, benzodiazepines, methamphetamines, and barbiturates.

In addition to assessment of psychopathology and substance use, subscales of the Wechsler Adult Intelligence Scale III (WAIS-III; Picture completion, Digit Symbol, Similarities, and Digit Span) were used to assess possible deficits in general neuropsychological function. The Chapman Perceptual Aberration Scale (PAS) was also administered in order to assess general disturbances in subjective perceptual experience (Chapman et al, 1978).

\section{RDK Moving Dot Procedure}

The moving dot paradigm was the same as that described previously (Krishnan et al, 2005). Briefly, subjects were asked to relax, keep their eyes open, and focus on the display during stimulus presentation. All stimuli were presented in a Power Macintosh computer $(5.9 \times 6.6$ degrees of visual angle; $80 \mathrm{~cd} / \mathrm{m}^{2}$ ). The experiment included three conditions: coherent motion, incoherent motion, and a static dot display. In the coherent condition, all dots in the RDK were displaced from left to right within the stimulus window. In the incoherent condition, all dots were displaced at randomly generated angles, whereas the dots were stationary in the static condition. A total of 100 dots were used to generate the RDK in each condition. The stimulus window subtended five degrees of the visual angle and the rate of displacement of dots was five degrees per second. The position of dots was refreshed every $107.5 \mathrm{~ms}(9.3 \mathrm{~Hz})$ for both the coherent and incoherent conditions. All trials were presented for $1500 \mathrm{~ms}$, with a 1.5 -s interval between trials. There were 100 trials in each condition. The conditions were randomized across trials and subjects were given brief breaks after every 50 trials.

\section{EEG Recording and Signal Analysis}

EEG recording and preprocessing. The EEG was recorded continuously (band pass $0.1-100 \mathrm{~Hz}$; sampling rate $1000 \mathrm{~Hz}$ ) from the scalp using a 32 channel electrode cap with a nose reference, along with additional electrodes to record the vertical electrooculogram (VEOG; Neuroscan SynAmps, Compumedics Neuroscan, Charlotte, NC). Electrode impedances were maintained below $10 \mathrm{k} \Omega$. The recorded EEG was segmented into epochs consisting of $1500 \mathrm{~ms}$ during stimulus presentation, along with $500 \mathrm{~ms}$ baseline and $500 \mathrm{~ms}$ offset period. Any trial with a voltage greater than $\pm 100 \mu \mathrm{V}$ was excluded from analysis. All subjects had at least $75 \%$ trials retained after artifact rejection. Ocular movement correction was applied using Gratton's algorithm (Gratton et al, 1983). All initial EEG processing was performed using commercially available software (Analyzer 2.0, Brain Products GmbH, Germany).

EEG signal analysis. Induced gamma activity was measured as mean trial power (MTP) using a time $\times$ frequency spectrogram with the Signal Processing and EEGLab toolbox in MATLAB (Delorme and Makeig, 2004; Rass et al, 2010; Skosnik et al, 2006b, 2012). For MTP, a baseline normalized event-related spectral perturbation (ERSP) was obtained by applying a Fast Fourier Transform (FFT) using a time-sliding window on single trial data. This results in a time $\times$ frequency transform consisting of a complex number for every time point, frequency, and trial. The $500 \mathrm{~ms}$ interval before stimulus onset was used as the baseline for computing the ERSP, and the sliding window had a duration of $128 \mathrm{~ms}$. After sufficient padding a frequency resolution of $0.98 \mathrm{~Hz}$ was obtained and the time resolution was $3.8 \mathrm{~ms}$. A Hanning window (100\%) was applied on the data before the FFT. No other taper functions were used. Thus, MTP represents the average of spectral power from individual trials after subtracting the mean from the baseline period ( $500 \mathrm{~ms}$ before stimulus onset). Power values in the gammaband range (frequency bins from 40 to $59 \mathrm{~Hz}$ ) were averaged using sequential $100 \mathrm{~ms}$ windows between onset and offset of the stimuli $(1500 \mathrm{~ms})$ for every subject and channel as reported previously (Krishnan et al, 2005). For statistical analysis, a single value was calculated for MTP from 40 to $59 \mathrm{~Hz}$ for the entire interval during stimulation (average MTP between 0 and $1500 \mathrm{~ms}$ ). Data from $\mathrm{Fz}, \mathrm{Cz}, \mathrm{Pz}$, and $\mathrm{Oz}$ were used for analysis of induced gamma. Finally, in order to rule out that baseline/resting gamma power affected the induced gamma results, an FFT was used to calculate single trial spectral power $(40-59 \mathrm{~Hz})$ during the stimulus-free baseline period ( -500 to $0 \mathrm{~ms}$ ).

For analysis of the transient visual evoked responses (N100 and P200), epochs were low-pass filtered at $15 \mathrm{~Hz}$ ( $24 \mathrm{~dB} /$ octave) before averaging, and were baseline corrected ( $500 \mathrm{~ms}$ prestimulus baseline) after averaging. Peak amplitude and latency values after stimulus onset were used as the dependent measures, and were obtained for each electrode within the time window of interest using an automated algorithm (Analyzer 2.0, Brain Products $\mathrm{GmbH}$ ). N100 was defined as the most negative voltage between 80 and $220 \mathrm{~ms}$ after stimulus onset and P200 was defined as the most positive voltage between 180 and $320 \mathrm{~ms}$ after stimulus onset. Data from the midline electrode sites $\mathrm{Fz}, \mathrm{Cz}, \mathrm{Pz}$, and $\mathrm{Oz}$ were used for analysis of the N100 and P200.

\section{Statistical Analysis}

For induced gamma activity (MTP), the primary comparisons of interest were the coherent $v s$ incoherent conditions and the coherent $v s$ static conditions. A repeated measures ANOVA was utilized to determine the between subjects factor of group (2), and the within-subjects factor of condition (2; coherent $v s$ incoherent and coherent $v s$ static) and electrode (4). For the transient N100 and P200 ERPs, amplitude and latency were assessed using repeated measures ANOVA that examined the between-subjects factor of group (2), and the within-subjects factors of condition (2; coherent $v s$ incoherent and coherent $v s$ static) and electrode (4). In order to examine baseline/resting gamma power, repeated measures ANOVA was used to assess the effect of group (2) and electrode (4). Greenhouse-Geisser corrections for nonsphericity were used where appropriate. The addition of gender, age, and level of alcohol or tobacco use as covariates did not alter the results of the induced gamma or ERP analyses. All EEG data were normally distributed, as assessed with Shapiro-Wilk tests for normality. In order to examine possible relationships between variables, Pearson's correlation coefficients were utilized. A criterion of $p<0.05$ 
was used throughout to determine statistical significance, and all tests were two tailed. All analyses were conducted in the software package PASW Statistics 18.0.

\section{RESULTS}

\section{Demographics, WAIS and PAS Scores, and Substance Use Data}

Table 1 provides basic demographic information, WAIS, PAS, and substance use data. A one-way ANOVA revealed that there were no significant differences between the groups in age, years of education, or WAIS-III subscale scores. The $\chi^{2}$ test showed that the gender proportion within each group was not significantly different (Table 1). Because of the stringent exclusion criteria (see above), alcohol and tobacco use rates for both groups were extremely low, and not clinically relevant. However, there was a significant difference in the average number of alcoholic drinks consumed per week between the two groups (Table 1). Furthermore, $62.5 \%$ of the sample of cannabis users met criteria for cannabis abuse or dependence. However, none of the subjects met DSM-IV criteria for alcohol or other substance abuse or dependence. Finally, a one-way ANOVA revealed a trend toward increased PAS scores in the cannabis group compared with healthy controls $(\mathrm{F}(1,45)=2.39, p=0.1$; Table 1$)$.

\section{Induced Gamma Activity}

Figures 1-3 illustrate induced gamma power between the groups for all three conditions from the four midline electrode sites. Figure 4 shows average MTP during the period of stimulation (0-1.5 s) for the groups in each of the conditions at electrode $\mathrm{Cz}$. For the comparison between the coherent and incoherent motion conditions, the repeated measures ANOVA revealed a main effect of condition $(\mathrm{F}(1,45)=45.22, p<0.001)$ indicating greater gamma power in the coherent motion condition (Figures 1 and 2). Furthermore, a significant group $\times$ condition interaction was observed $(\mathrm{F}(1,45)=6.27, p<0.016)$, indicating differential induced gamma activity in the coherent $v s$ incoherent motion conditions between the cannabis and control groups (Figure 4a and b). The post hoc ANOVAs comparing the groups in the coherent and incoherent conditions separately indicated that the cannabis group had decreased gamma power compared with controls in the coherent condition $(\mathrm{F}(4,42)=5.16, p<0.002)$. There was no significant difference between the groups in the incoherent condition $(\mathrm{F}(4,42)=0.99, p=0.42)$. A significant electrode $\times$ condition was also observed $(\mathrm{F}(3,135)=5.3, p<0.002)$.

For the comparison between the coherent motion and static conditions, the repeated measures ANOVA revealed a trend toward a condition $\times$ electrode interaction $(\mathrm{F}(3,135)=$ 2.40, $p<0.071)$ and a trend toward a condition $\times$ electrode $\times$ group interaction $(\mathrm{F}(3,135)=2.35, \quad p<0.075$; Figures 2,3 , and $4 \mathrm{~b}$ and $\mathrm{c}$ ). No other trends or significant effects were observed.

Finally, comparisons examining baseline/resting gamma power revealed a main effect of electrode $(\mathrm{F}(3,135)=23.0$, $p<0.001)$. However, no main effect of group $(\mathrm{F}(1,45)=$ $2.42, p=0.13)$ or electrode $\times$ group interaction $(\mathrm{F}(3,135)=$ $0.26, p=0.85$ ) was observed (data not shown).

\section{Transient ERPs (N100 and P200)}

For the comparison between the coherent and incoherent motion conditions for $\mathrm{N} 100$ amplitude, the repeated measures ANOVA revealed a main effect of electrode $(\mathrm{F}(3,135)=7.16$, $p<0.001)$. No other main effects or interactions were observed. For N100 latency, the ANOVA revealed a main effect of electrode $(\mathrm{F}(3,135)=23.75, p<0.001)$ and an electrode $\times$ condition interaction $(F(3,135)=7.07, p<0.001)$. No other significant effects were observed.

For P200 amplitude in the coherent $v s$ incoherent conditions, a main effect of electrode was observed $(F(3,135)=$ $49.84, p<0.001)$. No other main effects or interactions were observed. For P200 latency, the ANOVA revealed a main effect of electrode $(\mathrm{F}(3,135)=3.56, p<0.016)$ and an electrode $\times$ condition interaction $(\mathrm{F}(, 45)=4.64, p<0.004)$. No other main effects or interactions were observed. For illustrative purposes, grand-averaged N100-P200 waveforms and topographic head maps for the cannabis and healthy control groups from the coherent motion condition are shown in Figure 5.

For the comparison between the coherent motion and static conditions for N100 amplitude, the repeated measures ANOVA revealed a main effect of electrode $(\mathrm{F}(3,135)=4.82$, $p<0.003)$ and a group $\times$ condition interaction $(\mathrm{F}(1,45)=$ $4.46, p<0.04)$. However, post hoc ANOVAs examining N100 amplitude separately for the coherent $(F(4,42)=0.48$, $p=0.75)$ and static $(\mathrm{F}(4,142)=1.35, p=0.27)$ conditions revealed no group differences. For N100 latency, only a main effect of electrode was observed $(\mathrm{F}(3,135)=15.33$, $p<0.001)$. Finally, for P200 amplitude, the ANOVA revealed a main effect of condition $(\mathrm{F}(1,45)=15.27, p<0.001)$ and electrode $(\mathrm{F}(3,135)=59.10, p<0.001)$, and a condition $\times$ electrode interaction $(\mathrm{F}(3,135)=11.55, p<0.001)$. For $\mathrm{P} 200$ latency, no significant effects were observed.

\section{Correlations}

Potential associations (chosen a priori) between cannabis use variables (age of first use, total years of use, and number of joints in the past month) and induced gamma power (power values during the coherent condition at electrode $\mathrm{Cz}$ (where power was maximal)) and PAS scores were examined. Whereas no associations were observed for induced gamma activity, a significant positive correlation was observed for total years of cannabis use and PAS scores $(r=0.45$, $p<0.026$; Figure 6a). However, visualization of the data and further analysis revealed that one of the subjects represented an outlier (see circled data point in Figure 6a). Therefore, the correlation coefficient was recalculated with the removal of this subject. As can be seen in Figure $6 \mathrm{~b}$, the positive correlation between total years of cannabis use and PAS scores survived despite the exclusion of the outlier $(r=0.44, p<0.033)$.

\section{DISCUSSION}

The present study examined induced gamma oscillations during coherent motion perception via EEG in the context of chronic cannabinoids. As in previous work utilizing RDKs in humans (Krishnan et al, 2005; Siegel et al, 2007), the perception of coherent motion resulted in a robust 
HEALTHY CONTROLS

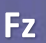

$\mathrm{Cz}$
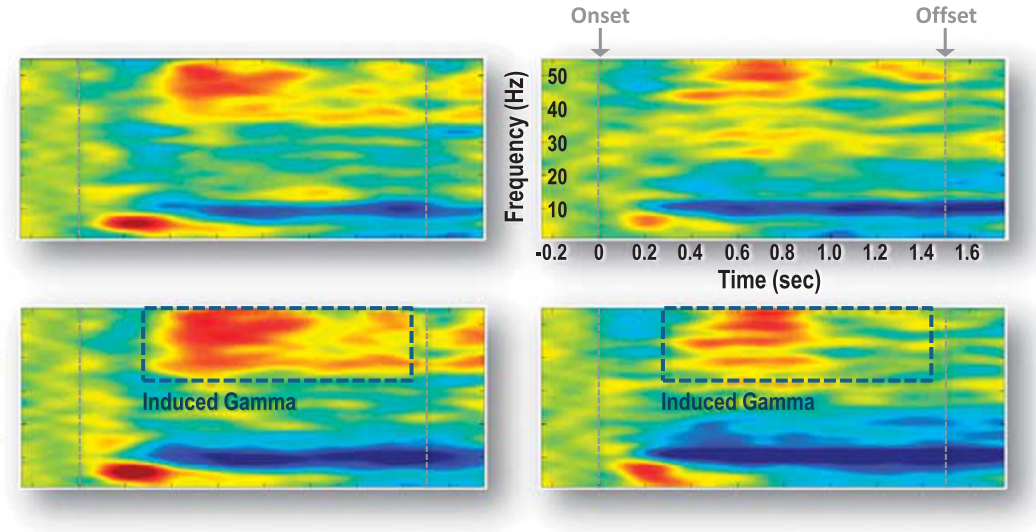

Pz
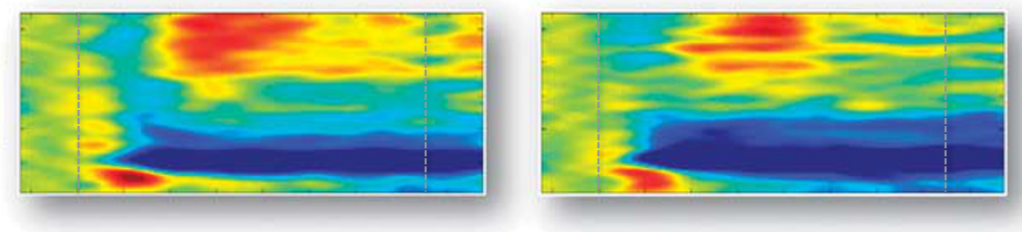

Oz
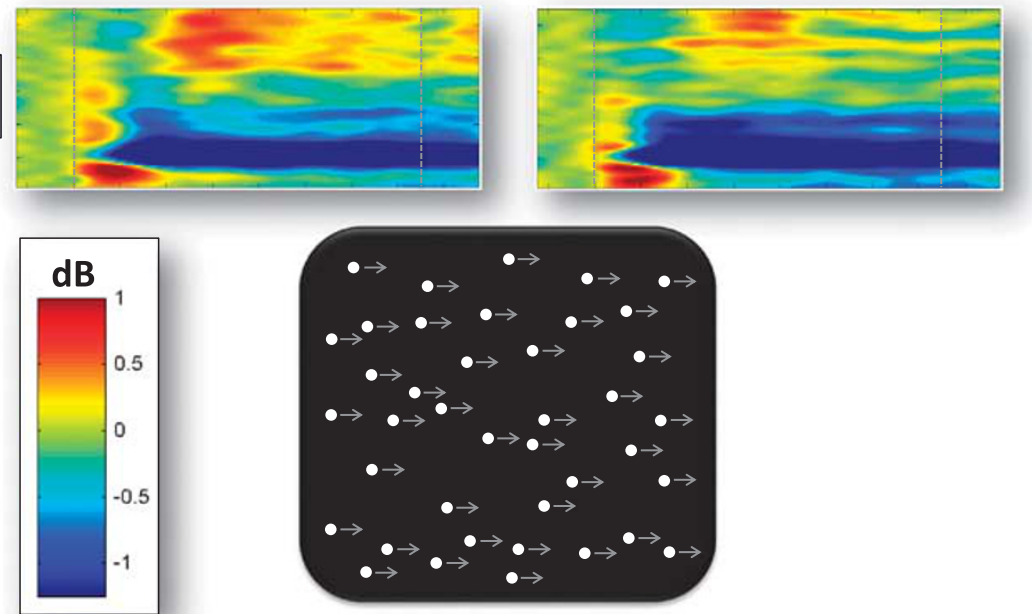

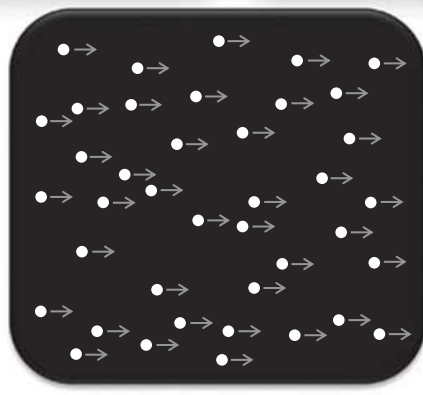

Coherent Motion

Figure I Grand-averaged time $\times$ frequency plots demonstrating mean trial power (MTP) for midline electrodes during the coherent motion condition for the healthy control and cannabis groups.

increase in induced gamma rhythms compared with incoherent motion or static stimuli (Figures 1-3). This replicates a host of animal and human studies demonstrating that gamma power is increased during the perception of coherent motion (Gray et al, 1990; Khayat et al, 2010; Krishnan et al, 2005; Kruse and Eckhorn, 1996; Lutzenberger et al, 1995; Muller et al, 1997; Naue et al, 2011; Schanze and Eckhorn, 1997; Siegel et al, 2007; Swettenham et al, 2009). Regarding the comparison of the control and cannabis groups, it was observed that cannabis users had significantly decreased induced gamma power in the coherent motion condition compared with healthy controls (Figures 1 and 4). This deficit was unlikely because of alterations in primary visual processing, as early ERPs (N100 and P200) to the RDK stimuli were not different between the control and cannabis groups (Figure 5). Finally, cannabis users exhibited greater self-reported perceptual anomalies (as indicated by higher scores on the PAS) that were positively correlated with total years of cannabis use (Figure 6).

This is the first study of induced gamma rhythms in the context of chronic exogenous cannabinoids in humans. The current results extend previous human work on evoked and steady-state gamma oscillations in cannabis users (Edwards et al, 2009; Skosnik et al, 2006a, 2012). For example, Skosnik et al (2012) demonstrated $40 \mathrm{~Hz}$ gamma-range deficits in spectral power using the auditory state paradigm. As in the current study, no differences were observed in early auditory ERPs (N100), indicating intact primary sensory processing. It thus appears that chronic cannabinoids influence synchronized oscillations in higher cortical areas (association cortex), whereas they have less impact on primary sensory cortex. The fact that association areas exhibit higher levels of CB1Rs as compared with primary sensory cortex provides anatomical support for this 
HEALTHY CONTROLS
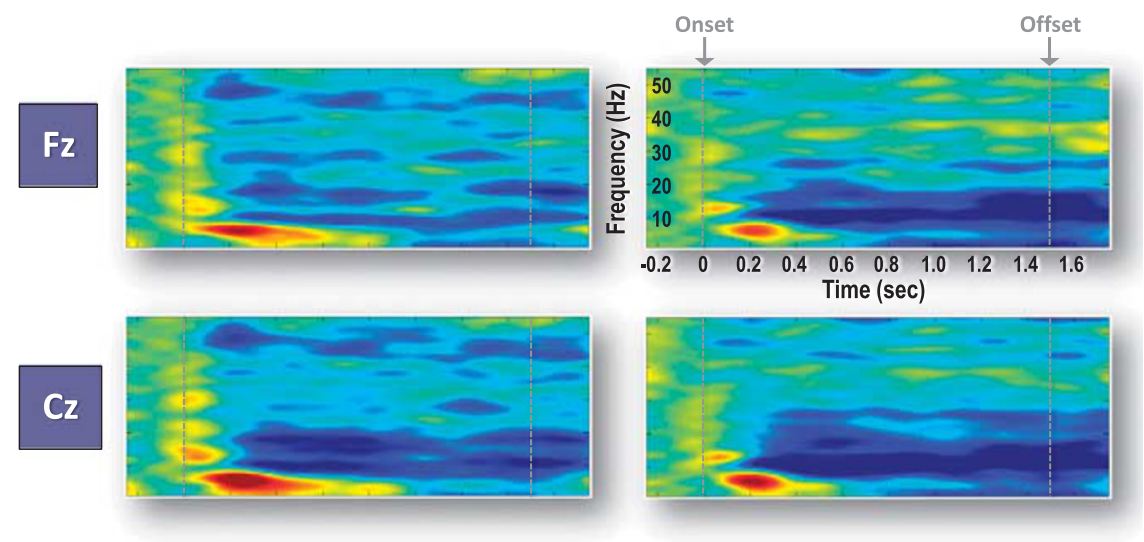

CANNABIS USERS
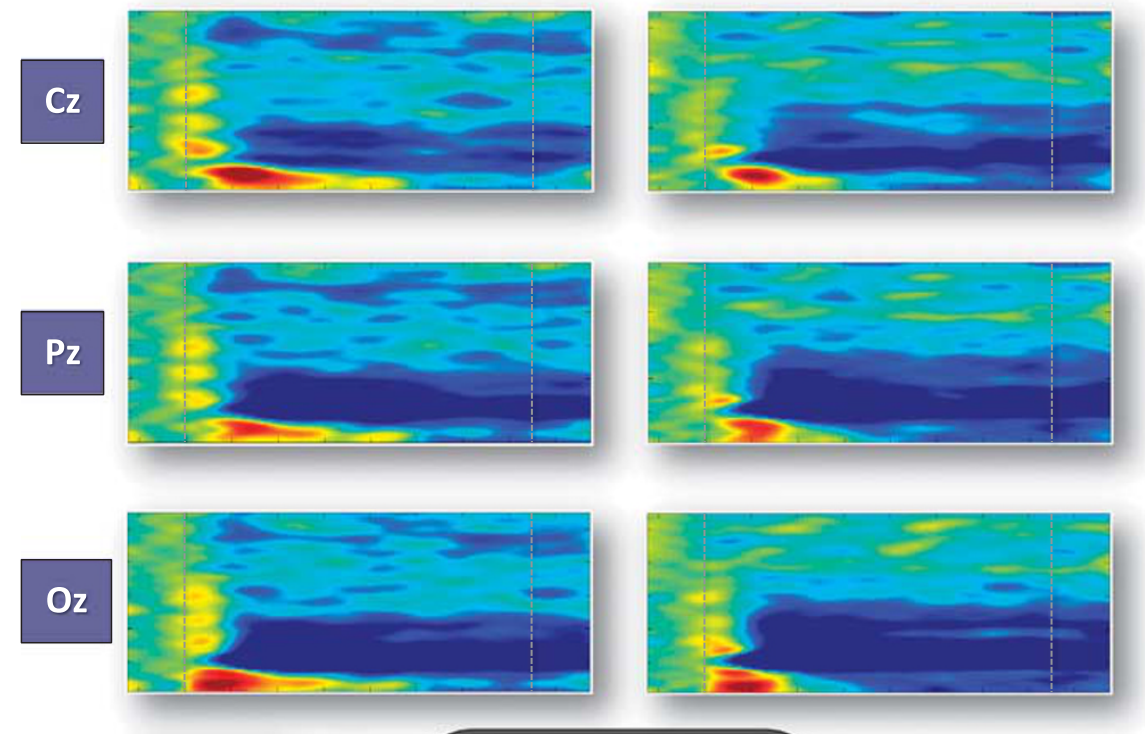

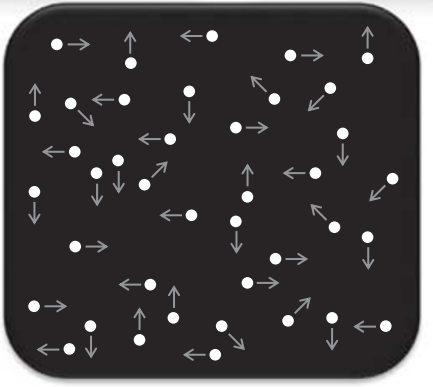

Incoherent Motion

Figure 2 Grand-averaged time $\times$ frequency plots demonstrating mean trial power (MTP) for midline electrodes during the incoherent motion condition for the healthy control and cannabis groups.

interpretation (Eggan and Lewis, 2007). In addition, total years of cannabis use were related to self-reported perceptual anomalies. This suggests that in addition to alterations in induced gamma oscillations, chronic cannabinoids are associated with lasting changes in perceptual processing.

The results of human studies demonstrating abnormalities in gamma-band neural oscillations in chronic cannabis users are also consistent with a host of in vitro and in vivo studies of acute cannabinoid effects in animals (Hajos et al, 2000, 2008; Morgan et al, 2008; Robbe et al, 2006; SalesCarbonell et al, 2013). These converging lines of evidence suggest that cannabinoids play a general role in the generation and maintenance of neural synchrony, particularly in the gamma range. Indeed, the fact that cannabinoids mediate GABA release in interneuron networks suggests that one of the functions of the CB1R is to maintain optimal excitatory-inhibitory balance that would be particularly relevant in brain regions with a high density of CB1Rs. Thus, acute and chronic exposure to exogenous cannabinoids would disrupt this balance, leading to altered inhibitory tone, with downstream perturbations in functionally relevant gamma (and perhaps theta) oscillations.

In terms of potential mechanisms whereby chronic cannabinoids may disrupt endocannabinoid dynamics, several possibilities exist. First, as THC competes with endocannabinoid transmitters at the CB1R, recent cannabis exposure may cause a compensatory increase in the synthesis and release of endocannabinoids such as anandamide and 2-arachidonoyl glycerol (2-AG). Indeed, a recent study in humans demonstrated that a single oral dose of $20 \mathrm{mg}$ THC resulted in significant increases in anandamide, 2-AG, palmitoyl ethanolamide, and oleoylethanolamide for several hours after administration (Walter et al, 2013). This 
HEALTHY CONTROLS

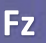

$\mathrm{Cz}$
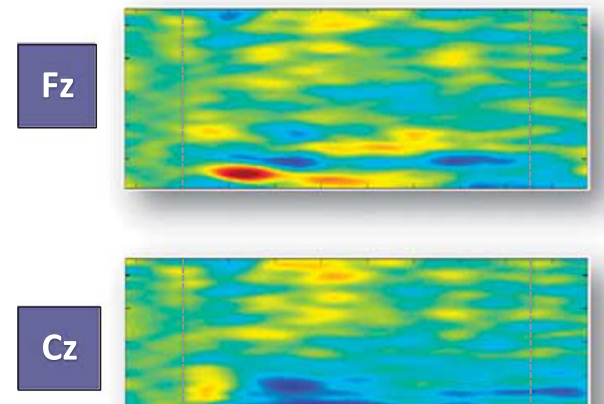

Pz
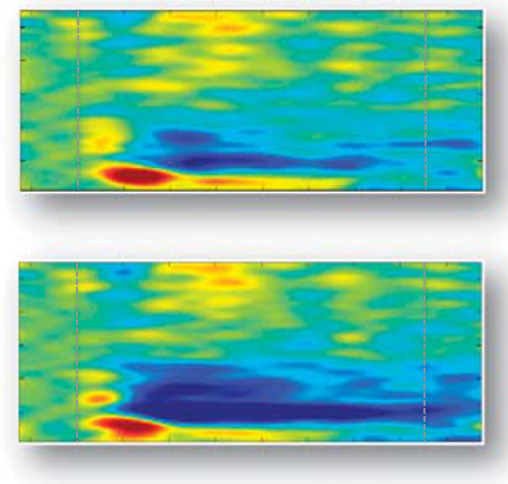

$\mathrm{Oz}$

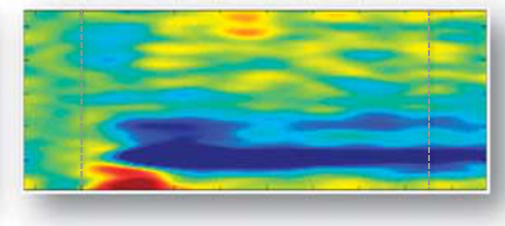

\section{CANNABIS USERS}
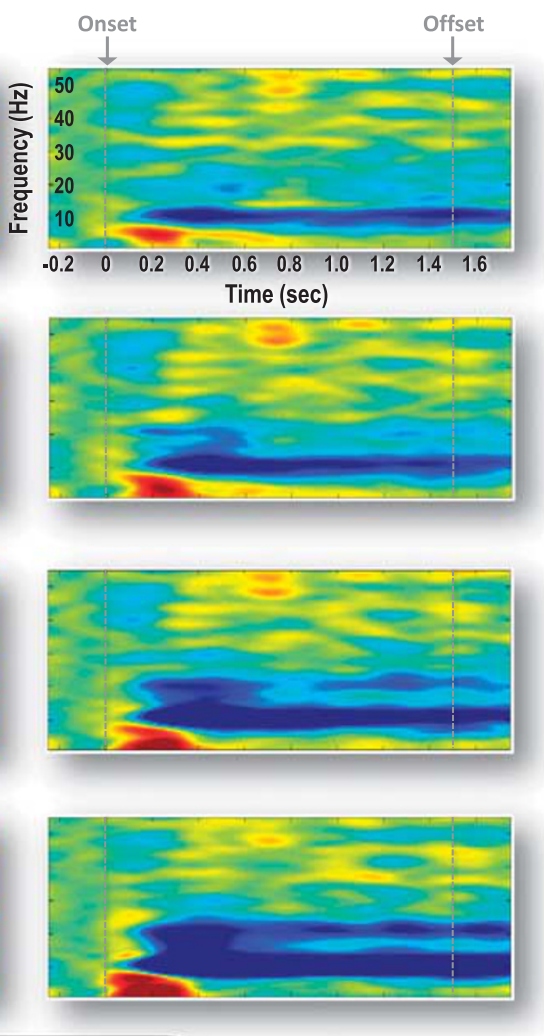

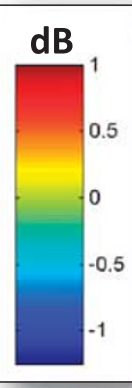

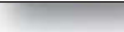

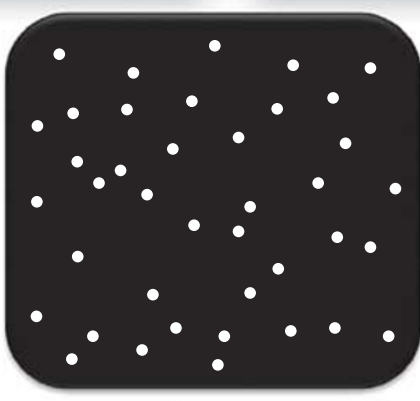

Static

Figure 3 Grand-averaged time $\times$ frequency plots demonstrating mean trial power (MTP) for midline electrodes during the static condition for the healthy control and cannabis groups.

effect was corroborated in a second experiment in rats with the synthetic cannabinoid WIN-55,212 (Walter et al, 2013). However, the fact that the present study examined induced gamma oscillations at a mean of $42.9 \mathrm{~h}$ after last cannabis exposure makes this mechanism unlikely. A second possibility is that chronic cannabis exposure produced significant CB1R downregulation in the cannabis group. Support for this notion comes from previous animal and human studies that have shown that chronic exposure to exogenous cannabinoids decreases the level of CB1Rs, an effect that can last for days to a week (Ceccarini et al, 2013; Hirvonen et al, 2012; Sim-Selley, 2003). Such decreases in CB1Rs could lead to alterations in GABA release, thus disrupting the ability of neural networks to generate synchronized neural oscillations. Indeed, a transcranial magnetic stimulation (TMS) study by Fitzgerald et al (2009) found that both heavy and light users of cannabis exhibit disruptions in short interval cortical inhibition that is indicative of altered GABA function. A final potential mechanism relates to the effect of cannabis on neurodevelopment. It is now well established that the endocannabinoid system plays a significant role in neurogenesis, neural specification, neural maturation, neuronal migration, axonal elongation, and glia formation (Harkany et al, 2007, 2008a, b). Furthermore, CB1R levels peak in adolescence, suggesting that young cannabis users may be particularly vulnerable to the development-altering effects of cannabis (Ellgren et al, 2008; Heng et al, 2011). In support of this idea, cannabis-related decreases in steady-state gamma power have been shown to be more profound in individuals who start using cannabis at an earlier age (Skosnik et al, 2012). Furthermore, a recent animal study demonstrated that chronic exposure to THC or WIN during adolescence permanently disrupted the ability to generate cortical 

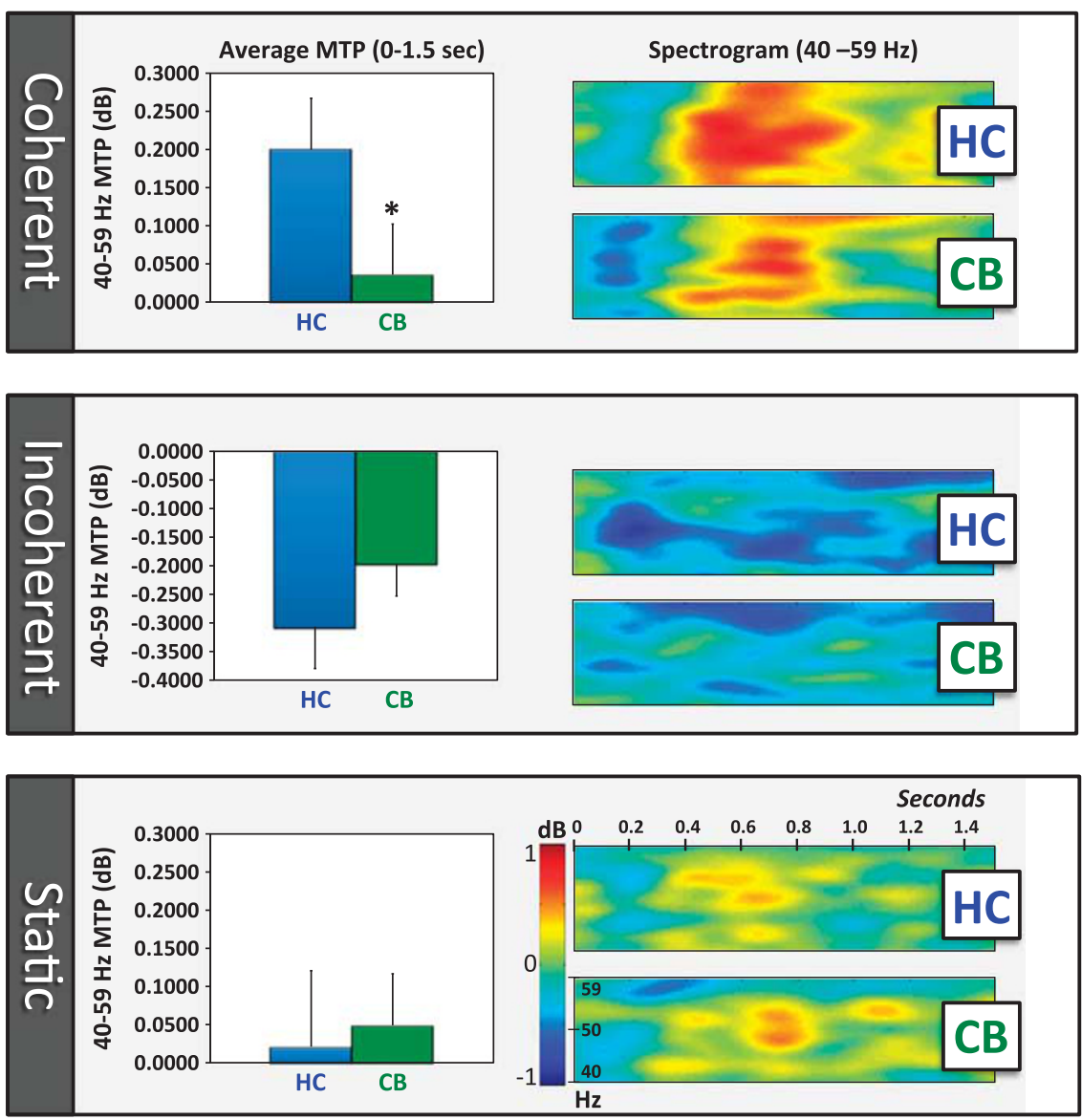

Figure 4 (Left) Average mean trial power during the period of stimulation $(0-1.5 \mathrm{~s})$ for each of the three experimental conditions for the healthy control $(\mathrm{HC})$ and cannabis (CB) groups (data from electrode $\mathrm{Cz}$ ). Cannabis users demonstrated decreased gamma power $(40-59 \mathrm{~Hz})$ in the coherent motion condition compared with healthy controls (top). (Right) Time $\times$ frequency spectrograms illustrating MTP from 40 to $59 \mathrm{~Hz}$ in each experimental condition for the control and cannabis groups (electrode Cz).
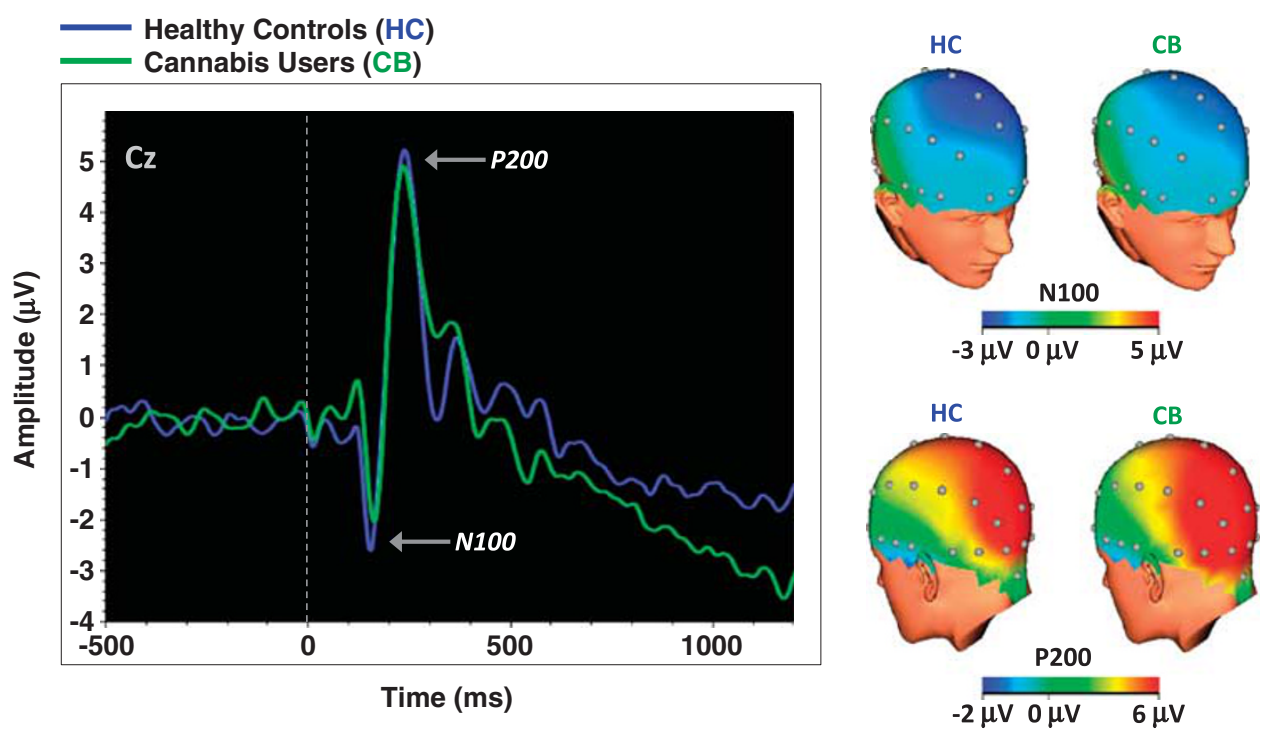

Figure 5 (Left) Grand-averaged ERPs to stimulus onset (NI00-P200) at electrode Cz for the healthy control (HC) and cannabis (CB) groups during the coherent motion condition. No differences were found between the groups in NI00-P200 in any of the experimental conditions, indicating normal primary visual processing. (Right) Grand-topographic maps for the NI00 (top) and P200 (bottom) for healthy controls and cannabis users from the coherent motion condition. 
a

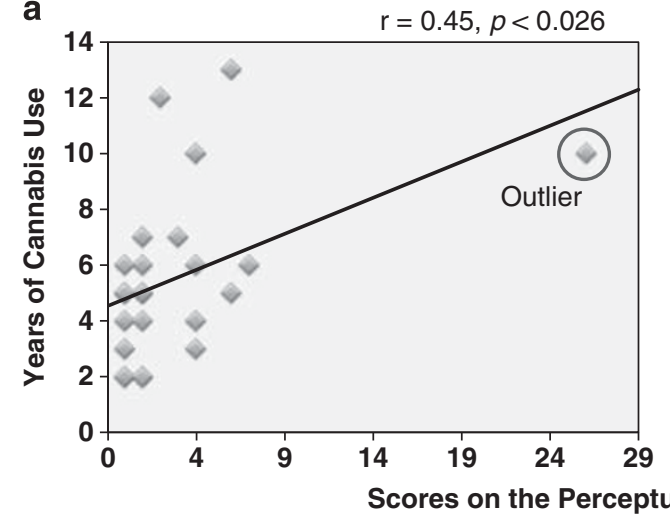

b

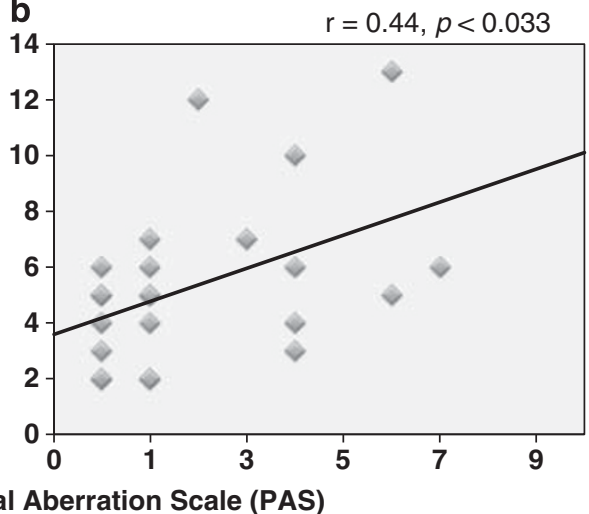

Figure 6 (Left) Correlation between PAS scores and total years of cannabis use. (Right) Correlation between PAS scores and total years of cannabis use after the removal of outlier.

oscillations in several frequencies (including gamma) when tested in adulthood. This effect was not observed in a comparison group in which THC and WIN was administered only in adult animals (Raver et al, 2013). Hence, earlier cannabis exposure during adolescence may alter neurodevelopmental trajectories that could permanently perturb the cortical 'machinery' necessary in the generation of synchronized oscillations.

Several limitations in the current study need to be addressed. First, there has been some debate as to whether visually induced gamma activity is neural in origin (Fries et al, 2008; Yuval-Greenberg et al, 2008). For example, Yuval-Greenberg et al (2008) reported that visually induced gamma correlated with miniature saccades, and such activity lasted for $<200 \mathrm{~ms}$ (Yuval-Greenberg et al, 2008). However, in the current study, the induced gamma activity was observed continuously for over $500-1000 \mathrm{~ms}$, and this is close to the entire period of the stimulation. It is known that microsaccades occur at low frequency $(<1 \mathrm{~Hz})$ (MartinezConde et al, 2009), and it is therefore unlikely that the induced gamma activity seen in the current study was influenced by microsaccades. Finally, activity from microsaccades is typically observed in frontal electrode sites, and the induced gamma observed here was largest at in centroparietal sites as in previous work from our group (Krishnan et al, 2005).

A second limitation is the cross-sectional nature of the experimental design that makes determining exact cause and effect relationship difficult. Hence, the observed effects could be because of residual THC, CB1R downregulation, cannabis withdrawal, or neurodevelopmental changes in cannabis users. Third, the cannabis plant contains nearly 70 phytocannabinoids, and hence it unclear what specific constituent plays a role in disrupting induced gamma oscillations. These limitations could partially be addressed in future studies by examining gamma oscillations in the context of acute cannabinoid administration in humans. Fourth, the limited age range of the sample raises questions about the generalizability of the current findings. Finally, although the cannabis group reported no other illicit drug use in the past 3 months, it is possible that the use of other substances in the remote past contributed to the findings. These limitations notwithstanding, the current data suggest that chronic exposure to cannabinoids may alter the ability to generate neural oscillations in the gamma range during Gestalt visual perception, and this may have implications for understanding the short- and long-term neurobehavioral effects of cannabis.

\section{FUNDING AND DISCLOSURE}

Deepak Cyril D'Souza has in the past 3 years or currently receives research grant support administered through Yale University School of Medicine from AbbVie, Eli Lilly, Forest Laboratories, and Pfizer; he is a consultant for Bristol Meyers Squibb and Johnson and Johnson. The other authors declare no conflict of interest.

\section{ACKNOWLEDGEMENTS}

This research project was funded in part by grants from NIDA (1 R03 DA019630-01A1; PI: PDS) and a NARSAD Young Investigator Award to PDS. We thank Chad R Edwards, Adam B Steinmetz, Daniel J Fridberg, Margaret S Brumbaugh, and Jennifer M. Vollmer for their assistance in data collection. Finally, this paper is dedicated to the memory of our dear friend and colleague, the late Dr R Andrew Sewell.

\section{REFERENCES}

Ali AB, Todorova M (2010). Asynchronous release of GABA via tonic cannabinoid receptor activation at identified interneuron synapses in rat CA1. Eur J Neurosci 31: 1196-1207.

Andersen RA (1997). Neural mechanisms of visual motion perception in primates. Neuron 18: 865-872.

Bacci A, Huguenard JR, Prince DA (2004). Long-lasting selfinhibition of neocortical interneurons mediated by endocannabinoids. Nature 431: 312-316.

Bertrand O, Tallon-Baudry C (2000). Oscillatory gamma activity in humans: a possible role for object representation. Int $J$ Psychophysiol 38: 211-223.

Bly LS (2012). Colorado, Washington OK recreational marijuana use. In: USA Today.

Bodor AL, Katona I, Nyiri G, Mackie K, Ledent C, Hajos N et al (2005). Endocannabinoid signaling in rat somatosensory cortex: laminar differences and involvement of specific interneuron types. J Neurosci 25: 6845-6856.

Born RT, Bradley DC (2005). Structure and function of visual area MT. Annu Rev Neurosci 28: 157-189. 
Brecht M, Goebel R, Singer W, Engel AK (2001). Synchronization of visual responses in the superior colliculus of awake cats. Neuroreport 12: 43-47.

Buzsaki G, Draguhn A (2004). Neuronal oscillations in cortical networks. Science 304: 1926-1929.

Buzsaki G, Wang XJ (2012). Mechanisms of gamma oscillations. Annu Rev Neurosci 35: 203-225.

Ceccarini J, Kuepper R, Kemels D, van Os J, Henquet C, Van Laere K (2013). [F]MK-9470 PET measurement of cannabinoid CB receptor availability in chronic cannabis users. Addict Biol (e-pub ahead of print 27 December 2013; doi:10.1111/adb.12116).

Chapman LJ, Chapman JP, Raulin ML (1978). Body-image aberration in schizophrenia. J Abnorm Psychol 87: 399-407.

D’Souza DC, Ranganathan M, Braley G, Gueorguieva R, Zimolo Z, Cooper $\mathrm{T}$ et al (2008). Blunted psychotomimetic and amnestic effects of delta-9-tetrahydrocannabinol in frequent users of cannabis. Neuropsychopharmacology 33: 2505-2516.

Delorme A, Makeig S (2004). EEGLAB: an open source toolbox for analysis of single-trial EEG dynamics including independent component analysis. J Neurosci Methods 134: 9-21.

Devane WA, Dysarz FA 3rd, Johnson MR, Melvin LS, Howlett AC (1988). Determination and characterization of a cannabinoid receptor in rat brain. Mol Pharmacol 34: 605-613.

Edwards CR, Skosnik PD, Steinmetz AB, O’Donnell BF, Hetrick WP (2009). Sensory gating impairments in heavy cannabis users are associated with altered neural oscillations. Behav Neurosci 123: 894-904.

Egertova M, Elphick MR (2000). Localisation of cannabinoid receptors in the rat brain using antibodies to the intracellular C-terminal tail of CB. J Comp Neurol 422: 159-171.

Eggan SM, Lewis DA (2007). Immunocytochemical distribution of the cannabinoid CB1 receptor in the primate neocortex: a regional and laminar analysis. Cereb Cortex 17: 175-191.

Eggan SM, Melchitzky DS, Sesack SR, Fish KN, Lewis DA (2010). Relationship of cannabinoid $\mathrm{CB} 1$ receptor and cholecystokinin immunoreactivity in monkey dorsolateral prefrontal cortex. Neuroscience 169: 1651-1661.

Ellgren M, Artmann A, Tkalych O, Gupta A, Hansen HS, Hansen SH et al (2008). Dynamic changes of the endogenous cannabinoid and opioid mesocorticolimbic systems during adolescence: THC effects. Eur Neuropsychopharmacol 18: 826-834.

Fitzgerald PB, Williams S, Daskalakis ZJ (2009). A transcranial magnetic stimulation study of the effects of cannabis use on motor cortical inhibition and excitability. Neuropsychopharmacology 34: 2368-2375.

Foldy C, Neu A, Jones MV, Soltesz I (2006). Presynaptic, activitydependent modulation of cannabinoid type 1 receptor-mediated inhibition of GABA release. J Neurosci 26: 1465-1469.

Fridberg DJ, Vollmer JM, O'Donnell BF, Skosnik PD (2011). Cannabis users differ from non-users on measures of personality and schizotypy. Psychiatry Res 186: 46-52.

Fries P, Scheeringa R, Oostenveld R (2008). Finding gamma. Neuron 58: 303-305.

Galambos R (1992). A comparison of certain gamma band (40-HZ) brain rhythms in cat and man. In: Başar EBullock T (eds) Induced Rhythms in the Brain. Birkhäuser: Boston, pp 201-216.

Galambos R, Makeig S, Talmachoff PJ (1981). A 40-Hz auditory potential recorded from the human scalp. Proc Natl Acad Sci USA 78: 2643-2647.

Gaoni Y, Mechoulam R (1971). The isolation and structure of delta-1-tetrahydrocannabinol and other neutral cannabinoids from hashish. J Am Chem Soc 93: 217-224.

Glass M, Dragunow M, Faull RL (1997). Cannabinoid receptors in the human brain: a detailed anatomical and quantitative autoradiographic study in the fetal, neonatal and adult human brain. Neuroscience 77: 299-318.
Gonzalez-Burgos G, Lewis DA (2008). GABA neurons and the mechanisms of network oscillations: implications for understanding cortical dysfunction in schizophrenia. Schizophr Bull 34: 944-961.

Gratton G, Coles MG, Donchin E (1983). A new method for off-line removal of ocular artifact. Electroencephalogr Clin Neurophysiol 55: $468-484$

Gray CM, Engel AK, Konig P, Singer W (1990). Stimulus-dependent neuronal oscillations in cat visual cortex: receptive field properties and feature dependence. Eur J Neurosci 2: 607-619.

Hajos M, Hoffmann WE, Kocsis B (2008). Activation of cannabinoid-1 receptors disrupts sensory gating and neuronal oscillation: relevance to schizophrenia. Biol Psychiatry 63: 1075-1083.

Hajos N, Katona I, Naiem SS, MacKie K, Ledent C, Mody I et al (2000). Cannabinoids inhibit hippocampal GABAergic transmission and network oscillations. Eur J Neurosci 12: 3239-3249.

Harkany T, Guzman M, Galve-Roperh I, Berghuis P, Devi LA, Mackie K (2007). The emerging functions of endocannabinoid signaling during CNS development. Trends Pharmacol Sci 28: 83-92.

Harkany T, Keimpema E, Barabas K, Mulder J (2008a). Endocannabinoid functions controlling neuronal specification during brain development. Mol Cell Endocrinol 286(1-2 Suppl 1): S84-S90.

Harkany T, Mackie K, Doherty P (2008b). Wiring and firing neuronal networks: endocannabinoids take center stage. Curr Opin Neurobiol 18: 338-345.

Heeger DJ, Boynton GM, Demb JB, Seidemann E, Newsome WT (1999). Motion opponency in visual cortex. J Neurosci 19: 71627174.

Heng L, Beverley JA, Steiner H, Tseng KY (2011). Differential developmental trajectories for CB1 cannabinoid receptor expression in limbic/associative and sensorimotor cortical areas. Synapse 65: 278-286.

Herkenham M, Lynn AB, Little MD, Johnson MR, Melvin LS, de Costa BR et al (1990). Cannabinoid receptor localization in brain. Proc Natl Acad Sci USA 87: 1932-1936.

Herrmann CS, Knight RT (2001). Mechanisms of human attention: event-related potentials and oscillations. Neurosci Biobehav Rev 25: $465-476$.

Hill EL, Gallopin T, Ferezou I, Cauli B, Rossier J, Schweitzer P et al (2007). Functional CB1 receptors are broadly expressed in neocortical GABAergic and glutamatergic neurons. J Neurophysiol 97: 2580-2589.

Hirvonen J, Goodwin RS, Li CT, Terry GE, Zoghbi SS, Morse C et al (2012). Reversible and regionally selective downregulation of brain cannabinoid CB1 receptors in chronic daily cannabis smokers. Mol Psychiatry 17: 642-649.

Hunt CA, Jones RT (1980). Tolerance and disposition of tetrahydrocannabinol in man. J Pharmacol Exp Ther 215: 35-44.

Johnson LA, Johnson RL, Alfonzo C (2011). Spice: a legal marijuana equivalent. Mil Med 176: 718-720.

Johnston LD, O'Malley PM, Bachman HG, Schulenberg JE (2012). Monitoring the Future national results on adolescent drug use: Overview of key findings, 2011. Institute for Social Research, The University of Michigan: Ann Arbor.

Kaiser J, Lutzenberger W (2003). Induced gamma-band activity and human brain function. Neuroscientist 9: 475-484.

Katona I, Sperlagh B, Magloczky Z, Santha E, Kofalvi A, Czirjak S et al (2000). GABAergic interneurons are the targets of cannabinoid actions in the human hippocampus. Neuroscience 100: 797-804

Khayat PS, Niebergall R, Martinez-Trujillo JC (2010). Frequencydependent attentional modulation of local field potential signals in macaque area MT. J Neurosci 30: 7037-7048.

Kleber HD, DuPont RL (2012). Physicians and medical marijuana. Am J Psychiatry 169: 564-568. 
Krishnan GP, Skosnik PD, Vohs JL, Busey TA, O’Donnell BF (2005). Relationship between steady-state and induced gamma activity to motion. Neuroreport 16: 625-630.

Kruse W, Eckhorn R (1996). Inhibition of sustained gamma oscillations $(35-80 \mathrm{~Hz})$ by fast transient responses in cat visual cortex. Proc Natl Acad Sci USA 93: 6112-6117.

Kruse W, Hoffmann KP (2002). Fast gamma oscillations in areas MT and MST occur during visual stimulation, but not during visually guided manual tracking. Exp Brain Res 147: 360-373.

Kwon JS, O'Donnell BF, Wallenstein GV, Greene RW, Hirayasu Y, Nestor PG et al (1999). Gamma frequency-range abnormalities to auditory stimulation in schizophrenia. Arch Gen Psychiatry 56: 1001-1005.

Large M, Sharma S, Compton MT, Slade T, Nielssen O (2011). Cannabis use and earlier onset of psychosis: a systematic metaanalysis. Arch Gen Psychiatry 68: 555-561.

Luck SJ, Mathalon DH, O'Donnell BF, Hamalainen MS, Spencer KM, Javitt DC et al (2011). A roadmap for the development and validation of event-related potential biomarkers in schizophrenia research. Biol Psychiatry 70: 28-34.

Lutzenberger W, Pulvermuller F, Elbert T, Birbaumer N (1995). Visual stimulation alters local $40-\mathrm{Hz}$ responses in humans: an EEG-study. Neurosci Lett 183: 39-42.

Martinez-Conde S, Macknik SL, Troncoso XG, Hubel DH (2009). Microsaccades: a neurophysiological analysis. Trends Neurosci 32: $463-475$.

Mehmedic Z, Chandra S, Slade D, Denham H, Foster S, Patel AS et al (2010). Potency trends of Delta9-THC and other cannabinoids in confiscated cannabis preparations from 1993 to 2008. J Forensic Sci 55: 1209-1217.

Meier MH, Caspi A, Ambler A, Harrington H, Houts R, Keefe RS et al (2012). Persistent cannabis users show neuropsychological decline from childhood to midlife. Proc Natl Acad Sci USA 109: E2657-E2664.

Melloni L, Molina C, Pena M, Torres D, Singer W, Rodriguez E (2007). Synchronization of neural activity across cortical areas correlates with conscious perception. J Neurosci 27: 2858-2865.

Moore TH, Zammit S, Lingford-Hughes A, Barnes TR, Jones PB, Burke $M$ et al (2007). Cannabis use and risk of psychotic or affective mental health outcomes: a systematic review. Lancet 370: 319-328.

Morgan NH, Stanford IM, Woodhall GL (2008). Modulation of network oscillatory activity and GABAergic synaptic transmission by CB1 cannabinoid receptors in the rat medial entorhinal cortex. Neural Plast 2008: 808564.

Muckli L, Singer W, Zanella FE, Goebel R (2002). Integration of multiple motion vectors over space: an fMRI study of transparent motion perception. Neuroimage 16: 843-856.

Muller MM, Junghofer M, Elbert T, Rochstroh B (1997). Visually induced gamma-band responses to coherent and incoherent motion: a replication study. Neuroreport 8: 2575-2579.

Naue N, Struber D, Frund I, Schadow J, Lenz D, Rach S et al (2011). Gamma in motion: pattern reversal elicits stronger gamma-band responses than motion. Neuroimage 55: 808-817.

ONDCP OoNDCP (2008). Marijuana: The Greatest Cause of Illegal Drug Abuse. Executive Office of the President: Washington, DC 20503.

Pantev C, Makeig S, Hoke M, Galambos R, Hampson S, Gallen C (1991). Human auditory evoked gamma-band magnetic fields. Proc Natl Acad Sci USA 88: 8996-9000.

Pertwee RG (1997). Pharmacology of cannabinoid CB1 and CB2 receptors. Pharmacol Ther 74: 129-180.

Pertwee RG (1999). Pharmacology of cannabinoid receptor ligands. Curr Med Chem 6: 635-664.

Pertwee RG, Howlett AC, Abood ME, Alexander SP, Di Marzo V, Elphick MR et al (2010). International Union of Basic and Clinical Pharmacology. LXXIX. Cannabinoid receptors and their ligands: beyond CB and CB. Pharmacol Rev 62: 588-631.
Picton TW, John MS, Dimitrijevic A, Purcell D (2003). Human auditory steady-state responses. Int J Audiol 42: 177-219.

Procon.org. (2011). Medical marijuana.

Rass O, Krishnan G, Brenner CA, Hetrick WP, Merrill CC, Shekhar A et al (2010). Auditory steady state response in bipolar disorder: relation to clinical state, cognitive performance, medication status, and substance disorders. Bipolar Disord 12: 793-803.

Raver SM, Haughwout SP, Keller A (2013). Adolescent cannabinoid exposure permanently suppresses cortical oscillations in adult mice. Neuropsychopharmacology 38: 2338-2347.

Roach BJ, Mathalon DH (2008). Event-related EEG time-frequency analysis: an overview of measures and an analysis of early gamma band phase locking in schizophrenia. Schizophr Bull 34: 907-926.

Robbe D, Montgomery SM, Thome A, Rueda-Orozco PE, McNaughton BL, Buzsaki G (2006). Cannabinoids reveal importance of spike timing coordination in hippocampal function. Nat Neurosci 9: 1526-1533.

Sales-Carbonell C, Rueda-Orozco PE, Soria-Gomez E, Buzsaki G, Marsicano G, Robbe D (2013). Striatal GABAergic and cortical glutamatergic neurons mediate contrasting effects of cannabinoids on cortical network synchrony. Proc Natl Acad Sci USA 110: 719-724.

SAMHSA (2012). Results from the 2011 National Survey on Drug Use and Health: Summary of National Findings. Substance Abuse and Mental Health Services Administration, NSDUH Series H-44, HHS Publication No. (SMA) 12-4713, Rockville, MD.

Schanze T, Eckhorn R (1997). Phase correlation among rhythms present at different frequencies: spectral methods, application to microelectrode recordings from visual cortex and functional implications. Int J Psychophysiol 26: 171-189.

Semple DM, Ramsden F, McIntosh AM (2003). Reduced binocular depth inversion in regular cannabis users. Pharmacol Biochem Behav 75: 789-793.

Siegel M, Donner TH, Oostenveld R, Fries P, Engel AK (2007). High-frequency activity in human visual cortex is modulated by visual motion strength. Cereb Cortex 17: 732-741.

Sim-Selley LJ (2003). Regulation of cannabinoid CB1 receptors in the central nervous system by chronic cannabinoids. Crit Rev Neurobiol 15: 91-119.

Singer W (1999). Neuronal synchrony: a versatile code for the definition of relations? Neuron 24: 49-65 111-125.

Skosnik PD, D'Souza DC, Steinmetz AB, Edwards CR, Vollmer JM, Hetrick WP et al (2012). The effect of chronic cannabinoids on broadband EEG neural oscillations in humans. Neuropsychopharmacology 37: 2184-2193.

Skosnik PD, Edwards CR, O’Donnell BF, Steffen A, Steinmetz JE, Hetrick WP (2008). Cannabis use disrupts eyeblink conditioning: evidence for cannabinoid modulation of cerebellar-dependent learning. Neuropsychopharmacology 33: 1432-1440.

Skosnik PD, Krishnan GP, Aydt EE, Kuhlenshmidt HA, O'Donnell BF (2006a). Psychophysiological evidence of altered neural synchronization in cannabis use: relationship to schizotypy. $A m J$ Psychiatry 163: 1798-1805.

Skosnik PD, Krishnan GP, Vohs JL, O’Donnell BF (2006b). The effect of cannabis use and gender on the visual steady state evoked potential. Clin Neurophysiol 117: 144-156.

Snowden RJ, Treue S, Erickson RG, Andersen RA (1991). The response of area MT and V1 neurons to transparent motion. J Neurosci 11: 2768-2785.

Solowij N, Stephens RS, Roffman RA, Babor T, Kadden R, Miller M et al (2002). Cognitive functioning of long-term heavy cannabis users seeking treatment. JAMA 287: 1123-1131.

Spencer KM, Salisbury DF, Shenton ME, McCarley RW (2008). Gamma-band auditory steady-state responses are impaired in first episode psychosis. Biol Psychiatry 64: 369-375. 
Swettenham JB, Muthukumaraswamy SD, Singh KD (2009). Spectral properties of induced and evoked gamma oscillations in human early visual cortex to moving and stationary stimuli. J Neurophysiol 102: 1241-1253.

Tallon-Baudry C (2009). The roles of gamma-band oscillatory synchrony in human visual cognition. Front Biosci (Landmark Ed) 14: 321-332.

Traub RD, Cunningham MO, Gloveli T, LeBeau FE, Bibbig A, Buhl EH et al (2003). GABA-enhanced collective behavior in neuronal axons underlies persistent gamma-frequency oscillations. Proc Natl Aced Sci USA 100: 11047-11052.

Traub RD, Whittington MA, Stanford IM, Jefferys JG (1996). A mechanism for generation of long-range synchronous fast oscillations in the cortex. Nature 383: 621-624.

Tsou K, Brown S, Sanudo-Pena MC, Mackie K, Walker JM (1998). Immunohistochemical distribution of cannabinoid CB1 receptors in the rat central nervous system. Neuroscience 83: 393-411.

Uhlhaas PJ, Pip G, Lima B, Mellon L, Neuenschwander S, Nikolic D et al (2009). Neural synchrony in cortical networks: history, concept and current status. Front Integr Neurosci 3: 17.
Cannabinoids and gamma oscillations

PD Skosnik et al

neg

3099

Uhlhaas PJ, Singer W (2010). Abnormal neural oscillations and synchrony in schizophrenia. Nat Rev Neurosci 11: 100-113.

Vardakou I, Piston C, Spiliopoulou C (2010). Spice drugs as a new trend: mode of action, identification and legislation. Toxicol Lett 197: $157-162$.

Walter C, Ferreiros N, Biscay P, Geisslinger G, Tegeder I, Lotsch J (2013). Exogenous delta(9)-tetrahydrocannabinol influences circulating endogenous cannabinoids in humans. J Chin Psychopharmacol 33: 699-705.

Wang XJ (2010). Neurophysiological and computational principles of cortical rhythms in cognition. Physiol Rev 90: 1195-1268.

Whittington MA, Faulkner HJ, Doheny HC, Traub RD (2000). Neuronal fast oscillations as a target site for psychoactive drugs. Pharmacol The 86: 171-190.

Whittington MA, Traub RD, Jefferys JG (1995). Synchronized oscillations in interneuron networks driven by metabotropic glutamate receptor activation. Nature 373: 612-615.

Yuval-Greenberg S, Tower O, Keren AS, Nelken I, Deouell LY (2008). Transient induced gamma-band response in EEG as a manifestation of miniature saccades. Neuron 58: 429-441.

Neuropsychopharmacology 